\title{
Tendinopathy: injury, repair, and current exploration
}

This article was published in the following Dove Press journal:

Drug Design, Development and Therapy

\author{
Kelsey Lipman' \\ Chenchao Wang ${ }^{2-4}$ \\ Kang Ting ${ }^{2}$ \\ Chia Soo ${ }^{4}$ \\ Zhong Zheng ${ }^{2}$
}

'David Geffen School of Medicine, ${ }^{2}$ Division of Growth and Development, Section of Orthodontics, School of Dentistry, University of California, Los Angeles, CA, USA; ${ }^{3}$ First Hospital of China Medical University, Shenyang, China; ${ }^{4}$ Division of Plastic and Reconstructive Surgery, Department of Orthopaedic Surgery, Orthopaedic Hospital Research Center, University of California, Los Angeles, CA, USA

Correspondence: Chia Soo

Orthopaedic Hospital Research Center, University of California, 635 Charles

E Young Drive South, Los Angeles,

CA 90024, USA

Tel +I 3107945479

Fax + I 3102067783

Email bsoo@ucla.edu

\section{Zhong Zheng}

Division of Growth and Development,

Section of Orthodontics, School of

Dentistry, University of California,

10833 Le Conte Avenue, Los Angeles,

CA 90095, USA

$\mathrm{Tel}+\mathrm{I} 3102065646$

Fax + I 3102067783

Email zzheng@dentistry.ucla.edu

\begin{abstract}
Both acute and chronic tendinopathy result in high morbidity, requiring management that is often lengthy and expensive. However, limited and conflicting scientific evidence surrounding current management options has presented a challenge when trying to identify the best treatment for tendinopathy. As a result of shortcomings of current treatments, response to available therapies is often poor, resulting in frustration in both patients and physicians. Due to a lack of understanding of basic tendon-cell biology, further scientific investigation is needed in the field for the development of biological solutions. Optimization of new delivery systems and therapies that spatially and temporally mimic normal tendon physiology hold promise for clinical application. This review focuses on the clinical importance of tendinopathy, the structure of healthy tendons, tendon injury, and healing, and a discussion of current approaches for treatment that highlight the need for the development of new nonsurgical interventions.
\end{abstract}

Keywords: tendinopathy, tendon injury, tendon repair, healing

\section{Introduction}

Though the incidence of tendinopathy is difficult to evaluate, it has been estimated that approximately $30 \%$ of consultations for musculoskeletal pain in a general practice setting are related to tendinopathy. ${ }^{1}$ While tendon injury remains an issue in the lives of a variety of patients and commonly occurs in the workplace, it has been reported that up to $30 \%-50 \%$ of sporting injuries involve tendinopathy. ${ }^{1,2}$ There is both an increase in the prevalence of musculoskeletal disease and an increase in cost per person in recent years, leading to rapidly rising economic impact of musculoskeletal conditions. The most recent assessment of economic burden of musculoskeletal disease demonstrates an increase in aggregate total expenditure for health care to have increased from US $\$ 367.1$ billion in 1996-1998 to $\$ 796.3$ billion in 2009-2011. ${ }^{3}$

Tendon injuries are often multifactorial, and can be classified as tendonitis, characterized by inflammation, and tendinosis, characterized by degenerative changes in tendon structure. ${ }^{4}$ More recently, the term "tendinopathy" has been adopted to encompass the clinical aspect of pain and reduced function of tendons. ${ }^{1,4}$ In most cases of tendinopathy, injury is due to the culmination of multiple pathological processes, rather than a single factor, that in combination lead to loss of tissue integrity and subsequent rupture. Statistical analysis reveals that the rotator cuff, Achilles, tibialis posterior, and patellar tendons are the most prone to pathology. ${ }^{4}$ Despite the use of currently available therapies, tendon injuries can result in disability that lasts for several months and ultimately results in a weaker tendon that is susceptible to further injury. ${ }^{5}$

While extrinsic factors, such as sports and physical activity, are often associated with tendon injury, additional intrinsic factors that can make an individual more or less likely to suffer from a tendon injury include age, sex, disease (ie, diabetes, rheumatoid arthritis), and genetic predisposition. ${ }^{4}$ Because tendon injury has a strong impact 
on patient quality of life and health care system spending, it is crucial to investigate further the molecular mechanisms involved in tendon repair in order to encourage the development of novel therapies for treatment.

\section{Tendon physiology}

Tendons are composed of a highly organized structure to allow for the transmission of large-magnitude forces between muscle and bone during daily activities. The structure relies on highly regulated interplay between the activity of local cell types and the regulation of extracellular matrix (ECM) composition (Figure 1). The ECM is composed of parallel collagen fibers that can be further divided into fascicles, fibrils, subfibrils, microfibrils, and tropocollagen components. ${ }^{6}$ Collectively, the bundled fibers are surrounded by connective tissue layers - epitenon and endotenon - that allow for frictionless movement and supply blood vessels, nerves, and lymphatics to deeper tendon structures. Regulation of this highly organized structure by tenocytes, tenoblasts, and tendon stem/progenitor cells (TSPCs) is crucial to maintain proper mechanical properties and prevent injury. ${ }^{6,7}$

\section{Tendon-cell niche}

Tenoblasts and tenocytes are tendon-specific cell types that comprise the vast majority of the cellular content within tendons. ${ }^{4}$ Tenocytes are considered fibroblast-like cells between collagen fibers and the endotenon capable of producing necessary components, such as type I collagen and other ECM molecules during growth and healing (Figure 1). Although the signaling process is not fully understood, it is believed that tenoblasts are stimulated to differentiate into terminally differentiated tenocytes in response to a variety of stimuli, including exercise and trauma, in order to induce proliferation and matrix remodeling. ${ }^{4,8}$

It has also been demonstrated that tendons contain TSPC niches capable of self-renewal and clonogenicity. ${ }^{7}$ Prior to identification of TSPCs by Bi et al in 2007, the development of fibrocartilage and ossification in response to injury and the expression of adipogenic, osteogenic, and chondrogenic differentiation pathways within tendon-derived immortalized cell lines suggested the presence of an stem cell (SC) population within tendons. ${ }^{7,9-11} \mathrm{Bi}$ et $\mathrm{al}^{7}$ also identified two ECM small leucine-rich proteoglycans (SLRPs) - fibromodulin (Fmod) and biglycan (Bgn) - as critical organizational components of the niche that act through modulation of BMP signaling.

The regulation of differentiation of these SCs within the niche is not precisely known, but proposed mechanisms include a combination of mechanical loading, composition/ microstructure of the ECM, vascular input, and metabolic activity. ${ }^{12,13}$ For example, culturing TSPCs with an aligned nanofibrous scaffold encouraged tenogenic lineage commitment compared to an osteogenic lineage commitment associated with a randomly oriented scaffold, supporting the notion that TSPCs receive topographical information from the surrounding ECM. ${ }^{12,14}$ FMOD has previously been used to reprogram human fibroblasts into a multipotent stage ${ }^{15,16}$ and elicit a fetal-like phenotype in adult fibroblasts during wound healing via delegate modulation of transforming growth factor (TGF)- $\beta$ signal transduction, ${ }^{17}$ demonstrating



Figure I Hierarchical structure of tendon.

Notes: Collagen alignment is based on organization into fascicles, fibers, and fibrils. Tenocytes, terminally differentiated from tenoblasts, are the main cellular component of tendons. Though the exact location of tendon stem cells is unknown, their presence has been confirmed. Blood vessels and nerves are also present within the structure, but are not shown. Data from Docheva et al ${ }^{4}$ and Nourissat et al. ${ }^{5}$ 
its ability to regulate cell fate within endogenous cell niches. ${ }^{15,18}$ Further research is needed fully to characterize the signaling that coordinates properties of the SC niche with TSPC differentiation and self-renewal.

\section{Tendon extracellular matrix}

Although extensive subdivisions exist within tendons, collagen fibers are considered the force-transmitting unit of the tendon. ${ }^{19,20}$ The ability of tendons to transmit force between the myotendinous junction and the osteotendinous junction is dependent upon the structural integrity between individual muscle fibers, as well as ECM composition and the fibrillar structure of the tendon. ${ }^{19}$ Most importantly, tissue strength depends on the ability of the collagen molecules to form an organized and cross-linked structure. ${ }^{21}$

Type I collagen predominates within the ECM of tendons, with type III collagen being the next-most abundant and critical in pathologic tendons and tendon-healing processes (Figure 2). ${ }^{22}$ Type I collagen alignment is recognized to be crucial for mechanical properties of tendons. As a result, research efforts are aimed at understanding the role of growth factors, transcription factors, and mechanical forces related to regulation of type I collagen-fibril spatial distribution. For example, TGF $\beta$ and FGFs have been shown to regulate collagen-architecture formation within tendons during development. ${ }^{23,24}$ In addition, the transcription factors scleraxis, Mohawk homeobox protein, and zinc-finger protein early growth response protein 1 (EGR1) regulate the formation of type I collagen within tendons through modulation of COL1A1 and COL1A2 gene expression (Figure 2). ${ }^{25-27}$

In addition to the highly ordered collagenous matrix within tendons, research is increasingly focusing on the roles of the noncollagenous matrix. ${ }^{28}$ The noncollagenous matrix is primarily composed of the fibrous protein elastin, glycoproteins, proteoglycans, and other molecules, such as collagen oligomeric matrix protein (COMP), lubrican, and tenascin $\mathrm{C}$ (Figure 2). ${ }^{29}$ Elastin fibers provide flexibility for distention during unidirectional elongation and provide

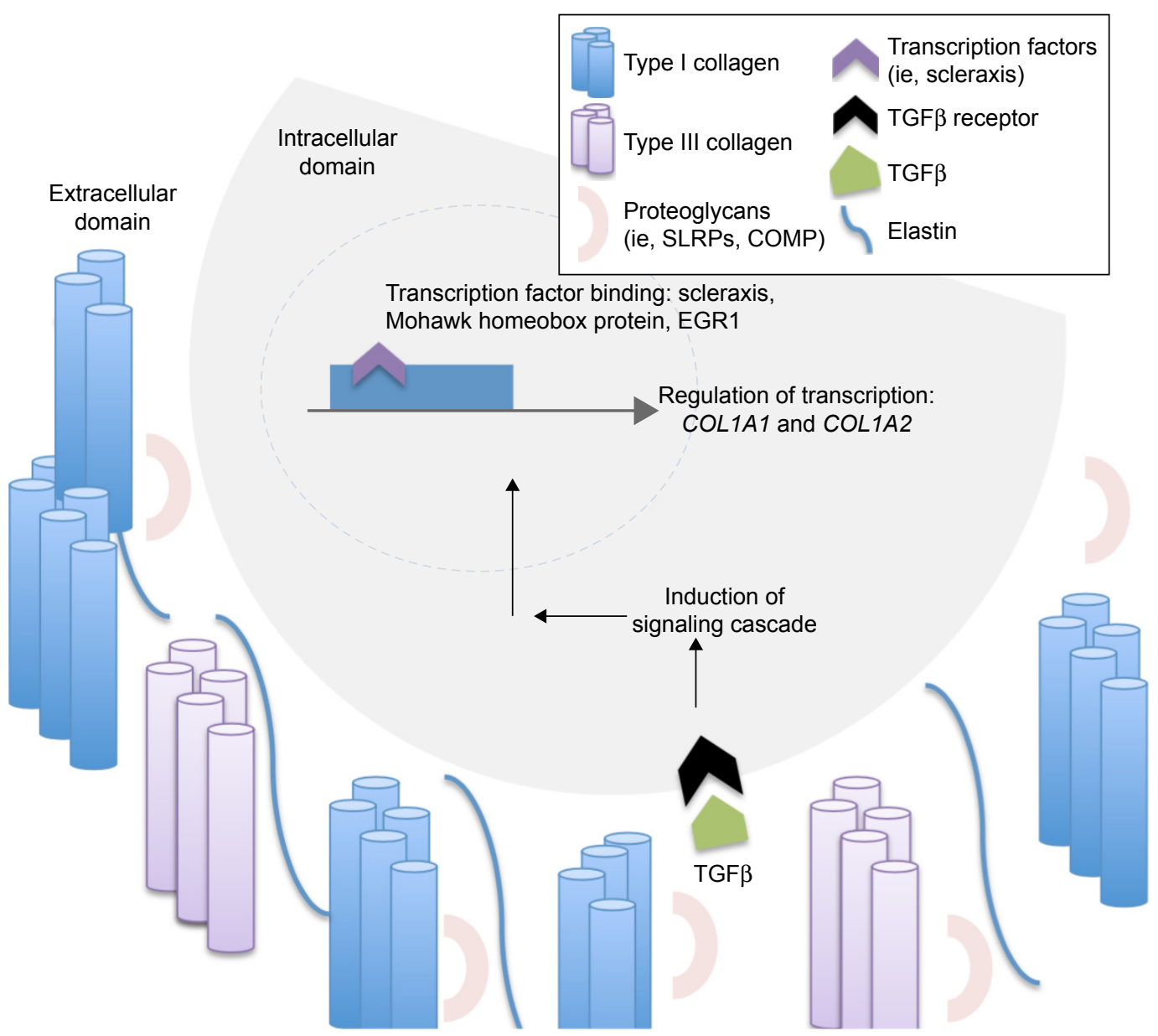

Figure 2 Representation of the interaction between tendon extracellular matrix and cellular signal transduction.

Note: With a predominance of type I in the healthy tendon, collagens interact with growth factors (such as TGF $\beta$ ) and proteoglycans (such as SLRPs and COMP) that regulate their synthesis and architectural organization. Data from references. ${ }^{22-33}$

Abbreviation: SLRPs, small leucine-rich proteoglycans. 
capabilities related to deformity and elastic recoil. However, the relatively low concentration of elastin simultaneously prevents excessive stretching during muscle contraction such that force is properly translated into articular movement. ${ }^{21}$ Most of the proteoglycans found within tendon are categorized as SLRPs, with decorin (Dcn) accounting for $80 \%$ of the total proteoglycan content and lower levels of Bgn, Fmod, and lumican (Lum). ${ }^{30}$

The role of noncollagenous matrix proteins during growth and development has been well characterized. Many of these proteins have the ability to regulate fibrillogenesis in terms of fibril diameter, alignment, and stability. ${ }^{31-33}$ For example, $B G N$ - and $D C N$-knockout mice contain thin, disorganized collagen fibrils and areas of calcification within the tendon. ${ }^{33,34}$ Interestingly, Bgn synthesis can be upregulated in $D C N$-null mice, suggesting the proteins have similar functions and may be able to play compensatory roles for each other. ${ }^{32}$ In a less severe manner compared to Bgn and Dcn, Fmod- and Lum-deficient mice also demonstrate increased cellularity and larger, irregularly shaped fibers. ${ }^{35}$ Similarly, knockout mice for various SLRPs have been shown to have disorganized dermal collagen architecture in the context of wound healing, leading to delayed wound closure and increased scar formation. ${ }^{36-38}$ For example, 14-day scars of Fmod-deficient mice demonstrate a wider range of fibril diameters, decrease in the orderly packing of fibrils with increased interfibrillar space, and contain scalloped edges with lateral fusion. ${ }^{36}$ In mature tendon, noncollagenous proteins have been proposed to modulate fiber and fascicle sliding, thereby regulating tendon viscoelastic properties. $^{39,40}$

Noncollagenous matrix components not only demonstrate roles in ECM assembly but also participate in the regulation of cell fate. As discussed previously, SLRPs are thought to regulate cell growth and differentiation through modulation of TSPC niches. ${ }^{34,41,42}$ The ability of Fmod to reprogram human fibroblasts into multipotent cells supports the idea that Fmod regulates cell fate through alterations in the cell niche microenvironment. Because Fmod is a $59 \mathrm{kD}$ ECM proteoglycan, it is unlikely that the molecule freely penetrates the membrane for reprogramming. Rather, Fmod most likely modulates expression of growth factors and cytokines in the ECM microenvironment that can lead to altered cell fate. ${ }^{15}$ In addition, it is likely that the various SLRPs in the noncollagenous matrix work as a unit to induce temporally and spatially specific signaling cues for cell differentiation during tendon development and tendon healing. Detailed characterization of each component of the noncollagenous matrix at hierarchical levels of tendons is needed to understand fully the structure-function relationship and apply the knowledge to tendon-injury treatment.

\section{Growth factors}

Tendon injury involves the production of multiple growth factors at various stages of healing that increase cellularity and attempt to regenerate tissue (Table 1). Though the roles of specific growth factors vary, they typically work synergistically with other signaling molecules and are

Table I Summary of tendon-healing process

\begin{tabular}{|c|c|c|c|c|c|c|}
\hline \multirow[t]{2}{*}{ Duration } & \multicolumn{2}{|c|}{ Inflammation* } & \multicolumn{2}{|c|}{ Proliferation* } & \multicolumn{2}{|c|}{ Remodeling* } \\
\hline & \multicolumn{2}{|l|}{ Days } & \multicolumn{2}{|l|}{ Weeks } & \multicolumn{2}{|c|}{ Months-years } \\
\hline \multirow[t]{3}{*}{$\begin{array}{l}\text { Overall } \\
\text { changes }\end{array}$} & \multicolumn{2}{|c|}{ Formation of hematoma } & \multicolumn{2}{|c|}{$\begin{array}{l}\text { Deposition of randomly organized } \\
\text { proteoglycans and collagen }\end{array}$} & \multicolumn{2}{|c|}{$\begin{array}{l}\text { Decrease in cellularity and matrix } \\
\text { production }\end{array}$} \\
\hline & \multicolumn{2}{|c|}{ Invasion of cells for phagocytosis } & \multicolumn{2}{|c|}{ Increased cellularity } & \multicolumn{2}{|c|}{ Transition from type III to type I collagen } \\
\hline & \multicolumn{2}{|c|}{ Release of proinflammatory cytokines } & \multicolumn{2}{|c|}{ Activation of TSPCs } & \multicolumn{2}{|c|}{ Increase collagen-fiber cross-linking } \\
\hline $\begin{array}{l}\text { Cellular } \\
\text { mediators }\end{array}$ & \multicolumn{2}{|c|}{ Neutrophils, macrophages } & \multicolumn{2}{|c|}{ Fibroblasts increase type III collagen } & \multicolumn{2}{|c|}{$\begin{array}{l}\text { Fibroblasts regulate type III-I collagen } \\
\text { transition }\end{array}$} \\
\hline \multirow[t]{6}{*}{$\begin{array}{l}\text { Molecular } \\
\text { mediators }\end{array}$} & IGF I & $\begin{array}{l}\text { Stimulation of proliferation and } \\
\text { migration }\end{array}$ & IGF I & $\begin{array}{l}\text { Stimulation of proliferation and } \\
\text { migration }\end{array}$ & IGFI & $\begin{array}{l}\text { Stimulation of proliferation and } \\
\text { migration }\end{array}$ \\
\hline & TGF $\beta$ & $\begin{array}{l}\text { Stimulates collagen production and } \\
\text { cell migration, regulates proteinases }\end{array}$ & TGF $\beta$ & $\begin{array}{l}\text { Stimulates collagen production and } \\
\text { cell migration, regulates proteinases }\end{array}$ & TGF $\beta$ & $\begin{array}{l}\text { Stimulates collagen production and } \\
\text { cell migration, regulates proteinases }\end{array}$ \\
\hline & PDGF & $\begin{array}{l}\text { Stimulates DNA and protein } \\
\text { synthesis }\end{array}$ & PDGF & $\begin{array}{l}\text { Stimulates DNA and protein } \\
\text { synthesis }\end{array}$ & FGF2 & $\begin{array}{l}\text { Regulates angiogenesis and cellular } \\
\text { migration }\end{array}$ \\
\hline & & & FGF2 & $\begin{array}{l}\text { Regulates angiogenesis and cellular } \\
\text { migration }\end{array}$ & $\begin{array}{l}\text { VEGF } \\
\text { MMPs }\end{array}$ & $\begin{array}{l}\text { Promotes neovascularization } \\
\text { Collagen degradation and }\end{array}$ \\
\hline & & & VEGF & Promote neovascularization & & reorganization \\
\hline & & & BMPs & Regulate differentiation of stem cells & & \\
\hline
\end{tabular}

Note: *Inflammatory, proliferative, and remodeling phases are characterized by structural changes regulated by cellular and molecular mediators that work synergistically to promote healing and increase tendon strength after an injury. $4,6,43-46,49-55,85,86$

Abbreviation: TSPCs, tendon stem/progenitor cells. 
upregulated throughout the tendon-repair process. The main growth factors involved in tendon healing that have been the focus of new repair therapies include IGF1, TGF, VEGF, PDGF, FGF2, and BMPs., ${ }^{43}$

IGF1 and TGF $\beta$ become active almost immediately after tissue injury and remain active throughout most phases of tendon healing. Multiple studies have demonstrated upregulation of IGF1 mRNA, protein, and receptors during and after soft-tissue injuries. ${ }^{44-46}$ IGF1 is postulated to stimulate proliferation and migration of fibroblasts at the injury site and to promote the production of ECM components during remodeling. Tsuzaki et al demonstrated that proliferation of tendon fibroblasts reached maximum levels when IGF1 was administered with PDGF, rather than as an individual application, supporting the idea that growth factors are synergistic in nature. ${ }^{45}$ PDGF is mainly involved in early stages of healing and induces synthesis of IGF1, subsequently stimulating DNA synthesis. ${ }^{47,48}$ PDGF also stimulates collagen and noncollagen protein production in the area of injury in a dose-dependent manner. ${ }^{43}$ TGF $\beta$ has been shown to have a wide variety of effects in all stages of healing, including stimulation of collagen production, regulation of fibronectin-binding patterns and proteinases, and stimulation of extrinsic cell migration. ${ }^{43,59}$

Unlike IGF1 and TGF $\beta$, which are active throughout the entirety of healing, VEGF is most active during the proliferation and remodeling phases..$^{50}$ Increases in VEGF correspond to subsequent vascular ingrowth from epitendinous and intratendinous blood sources toward the area of injury. ${ }^{51}$ This neovascularization serves to provide nutrients and additional growth factors to the injured site. FGF2 serves as a regulator of angiogenesis within wounded tissue. In a rabbit flexortendon wound-healing model, Chang et al demonstrated an increase in FGF2 mRNA expression in tenocytes within epitenon and infiltrating fibroblasts after transection and repair. ${ }^{52,53}$ BMPs stimulate mitogenesis and regulate differentiation of multipotent SCs in vitro and in vivo. ${ }^{54,55}$

Because growth factors interact with one another to regulate the tendon-healing environment, understanding the time course and function of growth factors in an individual sense has limited clinical applicability. As research progresses, the interplay between multiple growth factors will likely be a focus of therapeutic strategies, rather than administration of a single factor.

\section{Tendon injury and repair Overview of tendon injury}

As tendons transmit forces between muscle and bone during repeated motion, they become susceptible to acute and chronic injury. ${ }^{56}$ There are many mechanisms of injury that lead to tendinopathy or tendon rupture, and the injury can be due to a combination of both acute and chronic trauma. For example, tendon ruptures may occur in the setting of acute overload or laceration, but are often secondary to intrinsic pathology. ${ }^{56}$ Participating in a sporting activity is the most common etiologic factor for Achilles tendon rupture, but biopsies have shown degenerative changes in most ruptured Achilles tendons. ${ }^{57-59}$ As such, this type of injury is classified by some authors as acute trauma of chronically degenerated tendons. ${ }^{56}$

In addition to damage induced by stresses that are outside physiological limits, such as rupture or laceration, repetitive microtrauma that occurs within physiologic limits can induce tendinopathy and increase risk of acute and chronic injury. Repetitive loading can be detrimental to tendon structure, as the repair mechanism has less time to heal the microtrauma before subsequent stresses. ${ }^{60-62}$ Also, microtears can be induced by nonuniform force production and muscle activation that results in nonuniform loading of tendons. This indicates that both load magnitude and distribution are critical factors in the determination of tendon-injury etiology. ${ }^{60,61}$

Several ideas have been proposed to underlie the etiology of tendinopathy, including hypoxia, ischemic damage, oxidative stress, induction of apoptosis, and production of inflammatory cytokines. ${ }^{63-68}$ For instance, following ischemia induced by maximal tensile load, relaxation and subsequent generation of free radicals may play a role in tendinopathy. ${ }^{63}$ Supporting this idea is the upregulation of peroxiredoxin 5, an antioxidant enzyme present in human tenocytes, in cases of tendinopathy. ${ }^{64}$ In addition, localized hypoxia may result in failure to maintain necessary ATP levels and contribute to degeneration. ${ }^{65}$

It has also been demonstrated that strain application induces the production of protein kinases that regulate apoptosis of tenocytes. ${ }^{6}$ Furthermore, protein-kinase activity demonstrates a magnitude-dependent rather than frequency-dependent response. Animal models have shown that administration of harmful inflammatory mediators, such as prostaglandin $\mathrm{E}_{2}$ and IL6, induces tendinopathy histologically. ${ }^{67,68}$ Physiologic levels of cyclic stretching have also been shown to induce secretion of IL6 in tenocytes. ${ }^{67}$ Although the relative contribution of each of these biologic processes requires further investigation, tendinopathy is most likely due to a combination of these propositions. Although tendons have some regenerative capacity, their mechanical properties and highly ordered structural organization will not return to preinjury levels even after extended periods. ${ }^{69-71}$

Khan et al proposed the "biochemical hypothesis" to explain the pain associated with tendinopathy as it relates 
to the release of noxious stimuli and subsequent nociceptor stimulation. ${ }^{72,73}$ It has been demonstrated that tenocytes have the ability to produce signal substances that are typically confined to neuronal transmission, including substance P (SP), catecholamines, glutamate, and acetylcholine (ACh). ${ }^{73,74}$ Deeper investigation showed upregulation of tyrosine hydroxylase, the rate-limiting enzyme in catecholamine synthesis, and choline acetyltransferase, the biosynthetic enzyme for $\mathrm{ACh}$, in chronically injured tendons compared to control. ${ }^{74-78}$ Furthermore, immunohistochemical analysis and in situ hybridization have shown an increase in both protein and mRNA levels of SP and vesicular glutamate transporter 2, an indirect marker of glutamate release. ${ }^{79,80}$ It has also been shown that tenocytes themselves upregulate expression of receptors for catecholamines, ACh, and SP in chronic injury, suggesting that nonneuronal local substances may function in an autocrine or paracrine manner. ${ }^{74,76,78,79,81,82}$ However, further development is needed in regard to the biochemical hypothesis to determine if the signaling substances are causative in nature or merely a byproduct of disease, in order to determine the potential for treatments that target the biochemical milieu.

\section{Tendon-healing physiology}

Though the impact of mechanical and chemical stress depends on location and severity, response typically involves either inflammation of surrounding sheath, degeneration of collagen and ECM, or a combination of both. ${ }^{83}$ Subsequent tendon healing typically occurs through a sequential series of hemostasis, proliferation, and remodeling (Table 1). Although these phases can be described distinctly, they often overlap and vary in duration according to location and type of injury. ${ }^{6}$ Immediately after acute injury to tendons, changes in surrounding vascular structures and release of signaling molecules from intrinsic cells promote the formation of a hematoma for primary hemostasis. This initial step induces the release of growth factors and potent proinflammatory cytokines that draw inflammatory cells to the site of injury for the breakdown of the blood clot and surrounding necrotic tissue. The macrophages responsible for phagocytosis of surrounding fragments play a role in the proliferation of fibroblasts and angiogenesis to provide a means for delivery and synthesis of DNA, glycosaminoglycans, type III collagen, and other factors to begin generation of a new ECM. ${ }^{6,84,85}$

Extrinsic cells, including neutrophils and macrophages, that are key regulators in removing debris release a second generation of cytokines that transitions the healing process into a subsequent phase. ${ }^{83}$ The proliferative phase is characterized by disorganized deposition of granulation tissue and a peak in relative concentrations of type III collagen and DNA, setting the stage for further collagen synthesis and eventual transition from type III to type I collagen in subsequent stages. ${ }^{6,86}$

Remodeling involves a slowing of ECM deposition, longitudinal organization of collagen fibers within the tendon, and normalization of type III:I ratio of collagen-fiber types. ${ }^{6}$ In addition, it has been shown that MMPs are key regulators of ECM remodeling after tendon injury. ${ }^{83,87}$ Specifically, MMP9 and MMP13 play a role in collagen degradation, while MMP2, MMP3, and MMP14 participate in collagen remodeling. ${ }^{87}$ The concentration of various MMPs varies throughout the healing process. Although the remodeling phase generates a tendon that is structurally similar to the original, the injured tendon will remain mechanically inferior and have increased susceptibility to damage in the future compared to the uninjured tendon. ${ }^{43}$ The remodeling phase continues years beyond the original injury, and continuously tries to enhance the response of the tissue to applied forces. ${ }^{88}$

It is worth noting that tendon healing occurs by both intrinsic and extrinsic healing. Intrinsic healing results from proliferation of tenocytes within the epitenon and endotenon, while extrinsic healing results from invasion of cells from the surrounding sheath and synovium. ${ }^{89-91}$ The contribution of these healing mechanisms to repair may depend on the particular location and type of injury, but it has been demonstrated that intrinsic healing optimizes the repair process. Intrinsic healing preserves gliding within the tendon sheath, leading to fewer complications compared to the formation of adhesions associated with extrinsic healing. ${ }^{92}$ The differences in healing outcomes from intrinsic vs extrinsic healing can most likely be attributed to variability in tenocyte function according to site of origin. While tenocytes from tendon sheaths produce less collagen than epitenon/endotenon tenocytes, they have been shown to proliferate at an increased rate. ${ }^{93,94}$ Further investigation is needed to understand this variation and apply this concept to repair therapies.

\section{Current tendon-repair therapies}

Several therapies exist to modulate the tendon-healing process, but no single therapy has been reported to be consistently more effective than the others. ${ }^{95}$ Because the pathogenesis of tendinopathy is so complex and involves a variety of biological phenomena, current physical and biologic therapies attempt to modulate the repair process through a variety of pathways in hopes of mimicking complex native tissue. ${ }^{95}$ 
Table 2 Benefits and drawbacks of currently available treatment options

\begin{tabular}{|c|c|c|}
\hline Treatment method & Advantages & Shortcomings \\
\hline Low-energy laser therapy & $\begin{array}{l}\text { - Nonpharmacologic therapy } \\
\text { - Reduction of inflammatory markers } \\
\text { - Pain relief has been found when used in } \\
\text { addition to exercise therapy }\end{array}$ & $\begin{array}{l}\text { - Unknown mechanism of action } \\
\text { - Heterogeneous results of clinical trials } \\
\text { - Lack of optimized protocol for administration } \\
\text { (ie, timing of treatment, exposure-area size) }\end{array}$ \\
\hline Shock-wave therapy & $\begin{array}{l}\text { - Complications are negligible } \\
\text { - Convenient and cost-effective }\end{array}$ & $\begin{array}{l}\text { - Unknown mechanism of action } \\
\text { - Lack of standardized application parameters }\end{array}$ \\
\hline Steroid injection & $\begin{array}{l}\text { - Short-term pain relief and increased } \\
\text { functionality ( }<6 \text { weeks) }\end{array}$ & $\begin{array}{l}\text { - Increased possibility of tendon rupture } \\
\text { - Conflicting data regarding efficacy }\end{array}$ \\
\hline Growth-factor therapy & $\begin{array}{l}\text { - Injection is simple } \\
\text { - Well-studied targets }\end{array}$ & $\begin{array}{l}\text { - Short half-life requiring repeated injections } \\
\text { - Cost of protein production and purification } \\
\text { - Lacks spatiotemporal distribution of normal healing }\end{array}$ \\
\hline Gene therapy & $\begin{array}{l}\text { - Avoids immunogenicity } \\
\text { - Allows localized production of gene products }\end{array}$ & $\begin{array}{l}\text { - Expensive and complicated manufacturing of viral vectors } \\
\text { - Use of staging delivery is in its infancy }\end{array}$ \\
\hline
\end{tabular}

Note: Highlights the need for randomized control trials to provide consistency in results, a deeper understanding of tendon-cell biology, and the development of novel therapies that can better mimic natural physiology in a spatial and temporal manner. ${ }^{69,88-94,97-100,103-114,117,118,121,122}$

Such therapies include low-energy laser stimulation, injection of steroids, growth-factor injection, and newer gene-therapy developments. Table 2 provides a summary of the therapies discussed in this section.

\section{Low-energy laser therapy}

Although low-level laser therapy (LLLT) was first used to target soft-tissue injuries and inflammation, its applications have expanded to address a multitude of musculoskeletal injuries, including tendinopathy. ${ }^{96}$ The main mechanism by which LLLT promotes regeneration postinjury remains unclear, and current results of clinical trials suggest distinct mechanisms of action as possibilities. While some studies place an emphasis on the ability of LLLT to reduce inflammation and stimulate collagen production, ${ }^{96,97}$ other research suggests its primary role in healing to be ATP production, increased protein synthesis, and angiogenesis. ${ }^{98}$

The anti-inflammatory effect of LLLT in humans has been analyzed through microdialysis, a minimally invasive sampling technique that provides continuous measurement of peritendinous fluid. Through this technique, LLLT has been shown to reduce levels of the inflammatory marker prostaglandin $\mathrm{E}_{2}$ post-injury, supporting the relation of this therapy to inflammation suppression. ${ }^{96,99}$ It has been shown in animal models that the production of collagen is modulated by photostimulation with LLLT through an increase in neutral salt-soluble collagen and insoluble collagen and a decrease in pepsin soluble collagen. These changes support the indication that LLLT-treated tendons have a higher turnover rate of collagen and higher mechanical integrity compared to controls. ${ }^{97} \mathrm{LT}$ has also been shown to increase vessel numbers after injury, promoting neovascularization for the delivery of growth factors and nutrients to the site of damage. It has been proposed that LLLT stimulation induces the release of cytokines, FGF2, VEGF, and additional factors typically associated with neovascularization. ${ }^{98,100}$ Casalechi et al demonstrated that LLLT increases mRNA expression of the angiogenic factor VEGF in irradiated tissues. ${ }^{100}$

Not only is the choice to use LLLT for specific musculoskeletal conditions a topic of debate, but there are also contradictory suggestions regarding treatment parameters, such as power density, timing of treatment, and size of exposure region (Table 2). Because several literature reviews have not separately analyzed results based on laser wavelength or doses, it is possible that LLLT has a larger effect on tendon healing than is reported. ${ }^{101-103}$ Detailed analysis including consideration of administration parameters may help to explain the currently heterogeneous results among contradictory reviews. For example, Bjordal et al demonstrated that LLLT modulates biological mechanisms of tendon repair in a dose-dependent manner, but an optimum dose has yet to be determined. ${ }^{101,102}$ As more studies emerge that effectively demonstrate the validity of LLLT as a therapy for injury repair and investigate ideal application methods, LLLT has the potential to become more widely accepted for clinical use.

\section{Shock-wave therapy}

Shock waves (SWs) are typically biphasic and involve a peak pressure that is approximately 1,000 times that of ultrasound waves. ${ }^{104,105}$ In addition to high peak pressure, SWs have a fast initial rise in pressure, low tensile amplitude, short life cycle, and broad-frequency spectrum. ${ }^{104}$ They are generated through a fluid medium, typically water, and a coupling 
gel to direct transmission to biologic tissues when used for medical applications. ${ }^{104}$

In reference to orthopedic injury, the most important physical parameters of SW therapy include pressure distribution, energy density, and total acoustic energy. ${ }^{106,107}$ Though extracorporeal SW therapy (ESWT) was originally used for the treatment of renal calculi, ESWT is now used for several orthopedic applications. ${ }^{108}$ The exact mechanism by which ESWT promotes tendon healing is unknown, but several hypotheses have been proposed, including induction of tenocyte proliferation and collagen metabolism, increased collagen turnover, and enhanced neovascularization of injured tissue. ${ }^{109-111}$ Wang et al demonstrated that the induction of neovascularization at the site of injury was associated with the release of endothelial nitric oxide, VEGF, and proliferating cell antinuclear antigen. ${ }^{112}$ In addition, Zhang et al showed that ESWT at both high and low doses increased the expression of lubricin, a lubricating glycoprotein that facilitates tendon gliding. ${ }^{113}$ Most likely as a result of a combination of these proposed effects, ESWT has shown efficacy for the treatment of Achilles tendonitis and calcific tendonitis of the rotator cuff. ${ }^{114,115}$ However, in order to optimize application parameters, better understanding is needed of the precise cellular and molecular changes that are induced by ESWT.

\section{Steroid therapy}

Despite the questioned efficacy and poorly understood therapeutic mechanism, injection of corticosteroids remains a commonly used therapy for tendinopathy. ${ }^{116}$ Traditionally, corticosteroids are thought to regulate healing through regulation of anti-inflammatory transcription factors. ${ }^{117,118}$ However, several studies have reported an increase in inflammatory mediators after injection, most likely in response to glucocorticoid-induced damage, revealing the "anti-inflammatory" postulation to be an oversimplification in the case of tendon injury. ${ }^{116}$ While some studies have demonstrated that glucocorticoids result in increased collagen disorganization and collagen necrosis, some have demonstrated a positive effect on mechanical properties. ${ }^{116}$ For example, Dean et al investigated mechanical properties of tendons after steroid injection in 18 studies, and found that six showed a decrease in mechanical properties, three showed an increase, and nine showed no significant change. ${ }^{116}$ Smidt et al demonstrated that the effects of corticosteroid injection differ in the short term compared to the long term. Corticosteroid injection improved short-term outcomes ( $<6$ weeks), including pain reduction and an increase in global improvement. By contrast, intermediate (6 weeks to 6 months) and long-term
( $>6$ months) outcomes were shown to be statistically equivalent for corticosteroid injections compared to placebo and other conservative treatments. ${ }^{119}$ The ability of corticosteroid injections to modulate healing and reduce pain in the short term may partially explain their popularity as a treatment, despite lack of supportive evidence.

Whether administration is local or systemic, corticosteroid injection has previously been associated with increased risk of tendon rupture (Table 2). ${ }^{120-122}$ However, in reported cases involving systemic administration secondary to primary disease, it is difficult to determine whether the tendon injury is directly due to corticosteroid therapy or the primary disease, making the investigation into the exact mechanism of rupture particularly challenging. ${ }^{120}$ Recent research indicates that corticosteroid injection may temporarily induce a combination of apoptosis and increased expression of MMP3, a potent proteoglycan-degrading enzyme that plays a role in collagen degradation. ${ }^{123}$

Due to the association with tendon rupture, techniques are being investigated to increase the safety of using corticosteroid injections, specifically aimed at optimizing drug delivery. The use of fluoroscopy for corticosteroid injection involves the identification of peritendinous space using contrast medium. Once the contrast medium is injected and the space identified, a separate syringe is attached to the properly placed needle to inject the steroid. This administration technique has been shown to reduce major complications associated with corticosteroid injection, including tendon rupture, possibly because of reduced fibrosis, and vascular proliferation, limiting access of inflammatory mediators. ${ }^{124-126}$ Further research is needed to optimize injection-visualization techniques and for the accumulation of more consistent data demonstrating efficacy.

\section{Growth-factor therapy}

Because tendon injury promotes the production and release of multiple growth factors during the healing process, recombinant growth factors remain an area of investigation for potential tendon-healing therapies. ${ }^{95}$ Although no human studies investigating this method have been published, in vivo and in vitro experiments have demonstrated their efficacy and potential impact in the field. The involvement of growth factors in tendon healing has focused on IGF1, TGF $\beta$, VEGF, PDGF, and FGF2. ${ }^{43,127}$

The application of growth factors to the site of injury can be performed via local injection, operation, coated sutures, or implanted scaffolding material. Although there have been fewer studies on coated sutures and scaffolding methods, 
it has been suggested that growth factors using these methods are cleared from the site of injury at a slower rate compared to local injection. ${ }^{4}$ Studies investigating the role of growth factors have demonstrated their abilities to regulate differential expression of collagens and increase cell proliferation. ${ }^{4}$ Administration of multiple growth factors allowed for lower dosing requirements and showed increased potency compared to individual factors. ${ }^{128}$

The interplay between multiple growth factors throughout the healing process helps to explain the proposed efficacy of clinically used concentrates of autologous growth factors, such as platelet-rich plasma. Investigations on the use of autologous growth factors remain contradictory, because of the poorly characterized nature of the concentrate and variety of devices used to generate platelet-rich plasma. ${ }^{129}$ This variability creates an inconsistency in the composition of growth factors and additional cytokines contained in the mixture, making results challenging to analyze and compare (Table 2). ${ }^{130}$

Growth-factor therapy has shown some success for promoting tendon regeneration. However, it remains unlikely that a single growth factor will be able to regenerate normal tendons. One possible area for potential research involves the use of growth-factor combination therapy that involves administration of multiple growth factors in a temporal and spatial distribution that mimics normal physiology. This "growth-factor cocktail" may be able to modulate healing through a variety of processes and at various time points postinjury for more controlled regulation of healing. In addition, investigation into biomaterials that can deliver growth factors in a spatiotemporally defined manner has shown promise for mimicking the healing cascade. ${ }^{131}$

\section{Gene therapy}

By allowing a localized and focused production of gene products in the area of injury, gene therapy permits sustained and targeted production of growth factors and additional molecules that can undergo authentic posttranslational modification and avoid immunogenicity (Table 2). ${ }^{4}$ Because of the ability of viruses to infect cells with their genetic components, viruses are often manipulated to incorporate genes of choice while maintaining their ability to infect, simultaneously removing sequences needed for virulence. Currently, the recombinant viruses that have been investigated for delivery to tendons include adenovirus, lentivirus, retrovirus, and adenoassociated virus. ${ }^{4}$ Because viral vectors are expensive, complicated to manufacture, and have raise safety issues, there is an interest in using nonviral vector methods for gene delivery, including injection of naked DNA, electroporation, and sonoporation. ${ }^{132,133}$

In vivo and ex vivo delivery are the two gene-delivery strategies used for both viral and nonviral vectors. In vivo gene delivery involves the introduction of the vector directly via injection or other methods, including the use of geneactivated matrices. By contrast, ex vivo delivery involves genetic modification of cells prior to injection, providing a higher level of safety by avoiding direct introduction of virus into the system. Experiments in small-animal models have demonstrated efficacy using both viral and nonviral methods to introduce marker genes to ligaments and tendons using in vivo and ex vivo methodology. ${ }^{88}$ Because of the various factors that contribute to the tendon-repair process, investigators have approached introducing genes that affect a wide variety of biologic processes. For example, while some investigators focus on delivery of growth factors to promote differentiation of PCs into tenocytes, others focus on growth factors that enhance cellular and vascularity of the injured region. There is an interest in introducing multiple growth factors using a staged approach or polycistronic vector to mimic the multistep process of natural tendon healing. Other approaches are focused on driving multipotent PCs toward tenogenesis by introducing tenogenic cDNAs that prevent the formation of fat or bone during tendon repair.

Although gene therapy holds the enticing ability to manipulate the healing environment to generate favorable conditions for repair, its development in regard to the tendon is still in its infancy. The application finds challenges in identification of targets, tissue heterogeneity, host heterogeneity, and delivery systems. ${ }^{88}$ This technique will likely become a balance between searching for a single gene-therapy target and the development of a mixture of several targets for a multifactorial approach.

Gene therapy remains an appealing approach for the production of growth factors in situ, modulating natural healing and avoiding immunogenicity. However, new genetherapy approaches have investigated the use of nonviral methods for the introduction of SLRPs as an alternative to growth factors for modulation of healing. For example, liposome-based gene delivery of FMOD, a key regulator of collagen fibrillogenesis in injured tendons, has been demonstrated to promote rat Achilles tendon repair in vitro and in vivo. ${ }^{134}$

\section{Exercise}

Though this review focuses on potential biologic therapies to modulate tendon healing, it remains crucial to acknowledge 
the importance of tendon loading and its influence on repair. ${ }^{135}$ Rehabilitation regimens depend on the anatomy of the injured tendon, and require a delicate balance between the risk of adhesion and stiffness associated with immobilization and risk of injuring repaired tissue associated with too much loading. For example, passive motion exercises after flexor-tendon injury improve tendon gliding and repair strength compared to both immobilization and active loading, while protective immobilization has been shown to be most beneficial in a rat rotator-cuff model. ${ }^{136,137}$ Individualized exercise or immobilization regimens should be considered in addition to the strategies discussed herein to optimize tendon strength after an injury.

\section{Conclusion and outlook}

Despite current therapies, tendon structure and mechanical properties after injury have not yet approached those of healthy tendons. After the response to injury, tendons contain a higher concentration of type III collagen, thinner fibrils, and hypercellularity, resulting in a weaker tendon that is prone to future injury. Consequently, there remains a need for therapeutics that can direct the healing process toward the development of physiologically normal tendons.

In recent years, the field of tissue engineering has expanded to include improving the quality of tendon healing. Through a combination of cells, scaffolds, and bioactive molecules, tissue engineering combines molecular biology and materials science to replicate normal physiology more precisely. Newer advances in the field of nanotechnology, including the use of electrospun nanofiber scaffolds, are allowing for even more precise control of cellular behavior. For example, electrochemically aligned collagen threads can stimulate tenogenic differentiation of mesenchymal SCs by providing a uniformly aligned collagen substrate that mimics normal tendons. ${ }^{138}$ Additional efforts are being made to develop polymer-based nanofiber scaffolds with mechanical properties comparable to native tissue. ${ }^{139}$ These biomimetic scaffolds hold significant promise for tendon regeneration, but future studies are needed for scaffold optimization.

Tendon injuries remain a significant cause of both workrelated and sports-related injury. Although several therapies attempt to shorten healing time and restore tendons to optimal mechanical strength, there is presently limited scientific evidence supporting these therapies and their efficacy. In addition, it is widely debated which therapy is best depending on the specific type of tendinopathy. Future research is needed for the development of new techniques and delivery systems that mimic normal physiology in a temporal and spatial manner. Because such techniques are in their infancy, it will take substantial research to optimize them and direct the research toward clinical applications.

\section{Disclosure}

The authors report no conflicts of interest in this work.

\section{References}

1. Kaux JF, Forthomme B, Goff CL, Crielaard JM, Croisier JL. Current opinions on tendinopathy. J Sports Sci Med. 2011;10(2):238-253.

2. Scott A, Ashe MC. Common tendinopathies in the upper and lower extremities. Curr Sports Med Rep. 2006;5(5):233-241.

3. Yelin E, Weinstein S, King T. The burden of musculoskeletal diseases in the United States. Semin Arthritis Rheum. 2016;46(3):259-260.

4. Docheva D, Müller SA, Majewski M, Evans CH. Biologics for tendon repair. Adv Drug Deliv Rev. 2015;84:222-239.

5. Nourissat G, Berenbaum F, Duprez D. Tendon injury: from biology to tendon repair. Nat Rev Rheumatol. 2015;11(4):223-233.

6. Lin TW, Cardenas L, Soslowsky LJ. Biomechanics of tendon injury and repair. Journal Biomech. 2004;37(6):865-877.

7. Bi Y, Ehirchiou D, Kilts TM, et al. Identification of tendon stem/ progenitor cells and the role of the extracellular matrix in their niche. Nat Med. 2007;13(10):1219-1227.

8. Chuen FS, Chuk CY, Ping WY, Nar WW, Kim HL, Ming CK. Immunohistochemical characterization of cells in adult human patellar tendons. J Histochem Cytochem. 2004;52(9):1151-1157.

9. Fenwick S, Harrall R, Hackney R, et al. Endochondral ossification in Achilles and patella tendinopathy. Rheumatology (Oxford). 2002;41(4):474-476.

10. de Mos M, Koevoet WJ, Jahr H, et al. Intrinsic differentiation potential of adolescent human tendon tissue: an in-vitro cell differentiation study. BMC Musculoskelet Disord. 2007;8:16.

11. Salingcarnboriboon R, Yoshitake H, Tsuji K, et al. Establishment of tendon-derived cell lines exhibiting pluripotent mesenchymal stem cell-like property. Exp Cell Res. 2003;287(2):289-300.

12. Lui PP, Chan KM. Tendon-derived stem cells (TDSCs): from basic science to potential roles in tendon pathology and tissue engineering applications. Stem Cell Rev. 2011;7(4):883-897.

13. Wang JH, Komatsu I. Tendon stem cells: mechanobiology and development of tendinopathy. Adv Exp Med Biol. 2016;920:53-62.

14. Yin Z, Chen X, Chen JL, et al. The regulation of tendon stem cell differentiation by the alignment of nanofibers. Biomaterials. 2010;31(8): 2163-2175.

15. Zheng Z, Jian J, Zhang X, et al. Reprogramming of human fibroblasts into multipotent cells with a single ECM proteoglycan, fibromodulin. Biomaterials. 2012;33(24):5821-5831.

16. Li CS, Yang P, Ting K, et al. Fibromodulin reprogrammed cells: a novel cell source for bone regeneration. Biomaterials. 2016;83:194-206.

17. Zheng Z, James AW, Li C, et al. Fibromodulin reduces scar formation in adult cutaneous wounds by eliciting a fetal-like phenotype. Signal Transduct Target Ther. 2017;2:17050.

18. Jan AT, Lee EJ, Choi I. Fibromodulin: a regulatory molecule maintaining cellular architecture for normal cellular function. Int J Biochem Cell Biol. 2016;80:66-70.

19. de Aro AA, Vidal BC, Pimentel ER. Biochemical and anisotropical properties of tendons. Micron. 2012;43(2-3):205-214.

20. Magnusson SP, Hansen P, Kjaer M. Tendon properties in relation to muscular activity and physical training. Scand J Med Sci Sports. 2003; 13(4):211-223.

21. Zhang G, Young BB, Ezura Y, et al. Development of tendon structure and function: regulation of collagen fibrillogenesis. $J$ Musculoskelet Neuronal Interact. 2005;5(1):5-21.

22. Riley G. The pathogenesis of tendinopathy: a molecular perspective. Rheumatology (Oxford). 2004;43(2):131-142.

23. Lorda-Diez CI, Montero JA, Martinez-Cue C, Garcia-Porrero JA, Hurle JM. Transforming growth factors $\beta$ coordinate cartilage and tendon differentiation in the developing limb mesenchyme. J Biol Chem. 2009; 284(43):29988-29996. 
24. Pryce BA, Watson SS, Murchison ND, Staverosky JA, Dunker N, Schweitzer R. Recruitment and maintenance of tendon progenitors by TGF $\beta$ signaling are essential for tendon formation. Development. 2009;136(8):1351-1361.

25. Murchison ND, Price BA, Conner DA, et al. Regulation of tendon differentiation by scleraxis distinguishes force-transmitting tendons from muscle-anchoring tendons. Development. 2007;134(14):2697-2708.

26. Liu W, Watson SS, Lan Y, et al. The atypical homeodomain transcription factor Mohawk controls tendon morphogenesis. Mol Cell Biol. 2010; 30(20):4797-4807.

27. Guerquin MJ, Charvet B, Nourissat G, et al. Transcription factor EGR1 directs tendon differentiation and promotes tendon repair. J Clin Invest. 2013;123(8):3564-3576

28. Thorpe CT, Birch HL, Clegg PD, Screen HR. The role of the noncollagenous matrix in tendon function. Int J Exp Pathol. 2013;94(4): 248-259.

29. Yoon JH, Halper J. Tendon proteoglycans: biochemistry and function. J Musculoskelet Neuronal Interact. 2005;5(1):22-34

30. Samiric T, Ilic MZ, Handley CJ. Characterisation of proteoglycans and their catabolic products in tendon and explant cultures of tendon. Matrix Biol. 2004;23(2):127-140.

31. Kalamajski S, Oldberg A. The role of small leucine-rich proteoglycans in collagen fibrillogenesis. Matrix Biol. 2010;29(4):248-253.

32. Zhang G, Ezura Y, Chervoneva I, et al. Decorin regulates assembly of collagen fibrils and acquisition of biomechanical properties during tendon development. J Cell Biochem. 2006;98(6):1436-1449.

33. Kilts T, Ameye L, Syed-Picard F, et al. Potential roles for the small leucine-rich proteoglycans biglycan and fibromodulin in ectopic ossification of tendon induced by exercise and in modulating rotarod performance. Scand J Med Sci Sports. 2009;19(4):536-546.

34. Corsi A, Xu T, Chen XD, et al. Phenotypic effects of biglycan deficiency are linked to collagen fibril abnormalities, are synergized by decorin deficiency, and mimic Ehlers-Danlos-like changes in bone and other connective tissues. J Bone Miner Res. 2002;17(7):1180-1189.

35. Ezura Y, Chakravarti S, Oldberg A, Chervoneva I, Birk DE. Differential expression of lumican and fibromodulin regulate collagen fibrillogenesis in developing mouse tendons. J Cell Biol. 2000;151(4): 779-788.

36. Khorasani $\mathrm{H}$, Zheng Z, Nguyen $\mathrm{C}$, et al. A quantitative approach to scar analysis. Am J Pathol. 2011;178(2):621-628.

37. Smith MM, Melrose J. Proteoglycans in normal and healing skin. Adv Wound Care (New Rochelle). 2015;4(3):152-173.

38. Chen S, Birk DE. The regulatory roles of small leucine-rich proteoglycans in extracellular matrix assembly. FEBS J. 2013;280(10): 2120-2137.

39. Rigozzi S, Müller R, Stemmer A, Snedeker JG. Tendon glycosaminoglycan proteoglycan sidechains promote collagen fibril slidingAFM observations at the nanoscale. Journal Biomech. 2013;46(4): 813-818

40. Wood ML, Luthin WN, Lester GE, Dahners LE. Tendon creep is potentiated by NKISK and relaxin which produce collagen fiber sliding. Iowa Orthop J. 2003;23:75-79.

41. Iozzo RV. Matrix proteoglycans: from molecular design to cellular function. Annu Rev Biochem. 1998;67:609-652.

42. Ruoslahti E. Proteoglycans in cell regulation. J Biol Chem. 1989;264(23): 13369-13372.

43. Molloy T, Wang Y, Murrell G. The roles of growth factors in tendon and ligament healing. Sports Med. 2003;33(5):381-394.

44. Rubini M, Werner H, Gandini E, Roberts CT Jr, LeRoith D, Baserga R. Platelet-derived growth factor increases the activity of the promoter of the insulin-like growth factor-1 (IGF-1) receptor gene. Exp Cell Res. 1994;211(2):374-379.

45. Tsuzaki M, Brigman BE, Yamamoto J, et al. Insulin-like growth factor-I is expressed by avian flexor tendon cells. J Orthop Res. 2000;18(4): 546-556.

46. Vogt PM, Lehnhardt M, Wagner D, Steinau HU. Growth factors and insulin-like growth factor binding proteins in acute wound fluid. Growth Horm IGF Res. 1998;8 (Suppl B):107-109.
47. Lynch SE, Colvin RB, Antoniades HN. Growth factors in wound healing: single and synergistic effects on partial thickness porcine skin wounds. J Clin Invest. 1989;84(2):640-646.

48. Duffy FJ Jr, Seiler JG, Gelberman RH, Hergrueter CA. Growth factors and canine flexor tendon healing: initial studies in uninjured and repair models. J Hand Surg Am. 1995;20(4):645-649.

49. Chang J, Thunder R, Most D, Longaker MT, Lineaweaver WC. Studies in flexor tendon wound healing: neutralizing antibody to TGF- $\beta 1$ increases postoperative range of motion. Plast Reconstr Surg. 2000;105(1): $148-155$.

50. Boyer MI, Watson JT, Lou J, Manske PR, Gelberman RH, Cai SR. Quantitative variation in vascular endothelial growth factor mRNA expression during early flexor tendon healing: an investigation in a canine model. J Orthop Res. 2001;19(5):869-872.

51. Jackson JR, Minton JA, Ho ML, Wei N, Winkler JD. Expression of vascular endothelial growth factor in synovial fibroblasts is induced by hypoxia and interleukin 1 $\beta$. J Rheumatol. 1997;24(7):1253-1259.

52. Chang J, Most D, Thunder R, Mehrara B, Longaker MT, Lineaweaver WC. Molecular studies in flexor tendon wound healing: the role of basic fibroblast growth factor gene expression. J Hand Surg Am. 1998;23(6): 1052-1058.

53. Gabra N, Khayat A, Calabresi P, Khiat A. Detection of elevated basic fibroblast growth factor during early hours of in vitro angiogenesis using a fast ELISA immunoassay. Biochem Biophys Res Commun. 1994; 205(2):1423-1430.

54. Park A, Hogan MV, Kesturu GS, James R, Balian G, Chhabra AB. Adipose-derived mesenchymal stem cells treated with growth differentiation factor-5 express tendon-specific markers. Tissue Eng Part A. 2010;16(9):2941-2951.

55. Wolfman NM, Hattersley G, Cox K, et al. Ectopic induction of tendon and ligament in rats by growth and differentiation factors 5, 6, and 7, members of the TGF- $\beta$ gene family. J Clin Invest. 1997;100(2):321-330

56. Thomopoulos S, Parks WC, Rifkin DB, Derwin KA. Mechanisms of tendon injury and repair. J Orthop Res. 2015;33(6):832-839.

57. Astrom M, Rausing A. Chronic Achilles tendinopathy: a survey of surgical and histopathologic findings. Clin Orthop Relat Res. 1995;(316):151-164.

58. Järvinen TA, Kannus P, Maffulli N, Khan KM. Achilles tendon disorders: etiology and epidemiology. Foot Ankle Clin. 2005;10(2):255-266.

59. Raikin SM, Garras DN, Krapchev PV. Achilles tendon injuries in a United States population. Foot Ankle Int. 2013;34(4):475-480.

60. Nakama LH, King KB, Abrahamsson S, Rempel DM. Effect of repetition rate on the formation of microtears in tendon in an in vivo cyclical loading model. J Orthop Res. 2007;25(9):1176-1184.

61. Nakama LH, King KB, Abrahamsson S, Rempel DM. Evidence of tendon microtears due to cyclical loading in an in vivo tendinopathy model. J Orthop Res. 2005;23(5):1199-1205.

62. Arndt AN, Komi PV, Brüggemann GP, Lukkariniemi J. Individual muscle contributions to the in vivo Achilles tendon force. Clin Biomech (Bristol, Avon). 1998;13(7):532-541.

63. Goodship AE, Birch HL, Wilson AM. The pathobiology and repair of tendon and ligament injury. Vet Clin North Am Equine Pract. 1994; 10(2):323-349.

64. Wang MX, Wei A, Yuan J, et al. Antioxidant enzyme peroxiredoxin 5 is upregulated in degenerative human tendon. Biochem Biophys Res Commun. 2001;284(3):667-673

65. Birch HL, Rutter GA, Goodship AE. Oxidative energy metabolism in equine tendon cells. Res Vet Sci. 1997;62(2):93-97.

66. Arnoczky SP, Tian T, Lavagnino M, Gardner K, Schuler P, Morse P. Activation of stress-activated protein kinases (SAPK) in tendon cells following cyclic strain: the effects of strain frequency, strain magnitude, and cytosolic calcium. J Orthop Res. 2002;20(5):947-952.

67. Skutek M, van Griensven M, Zeichen J, Brauer N, Bosch U. Cyclic mechanical stretching enhances secretion of interleukin 6 in human tendon fibroblasts. Knee Surg Sports Traumatol Arthrosc. 2001;9(5): 322-326.

68. Stone D, Green C, Rao U, et al. Cytokine-induced tendinitis: a preliminary study in rabbits. J Orthop Res. 1999;17(2):168-177. 
69. Frank C, McDonald D, Bray D, et al. Collagen fibril diameters in the healing adult rabbit medial collateral ligament. Connect Tissue Res. 1992;27(4):251-263.

70. Frank C, McDonald D, Shrive N. Collagen fibril diameters in the rabbit medial collateral ligament scar: a longer term assessment. Connect Tissue Res. 1997;36(3):261-269.

71. Frank C, Woo SL, Amiel D, Harwood F, Gomez M, Akeson W. Medial collateral ligament healing: a multidisciplinary assessment in rabbits. Am J Sports Med. 1983;11(6):379-389.

72. Khan KM, Cook JL, Maffulli N, Kannus P. Where is the pain coming from in tendinopathy? It may be biochemical, not only structural, in origin. Br J Sports Med. 2000;34(2):81-83.

73. Danielson P. Reviving the "biochemical" hypothesis for tendinopathy: new findings suggest the involvement of locally produced signal substances. Br J Sports Med. 2009;43(4):265-268.

74. Bjur D, Danielson P, Alfredson H, Forsgren S. Presence of a nonneuronal cholinergic system and occurrence of up- and down-regulation in expression of M2 muscarinic acetylcholine receptors: new aspects of importance regarding Achilles tendon tendinosis (tendinopathy). Cell Tissue Res. 2008;331(2):385-400.

75. Danielson P, Alfredson H, Forsgren S. Studies on the importance of sympathetic innervation, adrenergic receptors, and a possible local catecholamine production in the development of patellar tendinopathy (tendinosis) in man. Microsc Res Tech. 2007;70(4):310-324.

76. Bjur D, Danielson P, Alfredson H, Forsgren S. Immunohistochemical and in situ hybridization observations favor a local catecholamine production in the human Achilles tendon. Histol Histopathol. 2008;23(2):197-208.

77. Danielson P, Alfredson H, Forsgren S. In situ hybridization studies confirming recent findings of the existence of a local nonneuronal catecholamine production in human patellar tendinosis. Microsc Res Tech. 2007;70(10):908-911.

78. Danielson $\mathrm{P}$, Alfredson H, Forsgren S. Immunohistochemical and histochemical findings favoring the occurrence of autocrine/paracrine as well as nerve-related cholinergic effects in chronic painful patellar tendon tendinosis. Microsc Res Tech. 2006;69(10):808-819.

79. Andersson G, Danielson P, Alfredson H, Forsgren S. Presence of substance $\mathrm{P}$ and the neurokinin-1 receptor in tenocytes of the human Achilles tendon. Regul Pept. 2008;150(1-3):81-87.

80. Scott A, Alfredson H, Forsgren S. VGluT2 expression in painful Achilles and patellar tendinosis: evidence of local glutamate release by tenocytes. J Orthop Res. 2008;26(5):685-692.

81. Forsgren S, Danielson P, Alfredson H. Vascular NK-1 receptor occurrence in normal and chronic painful Achilles and patellar tendons: studies on chemically unfixed as well as fixed specimens. Regul Pept. 2005;126(3):173-181.

82. Danielson P, Andersson G, Alfredson H, Forsgren S. Extensive expression of markers for acetylcholine synthesis and of M2 receptors in tenocytes in therapy-resistant chronic painful patellar tendon tendinosis: a pilot study. Life Sci. 2007;80(24-25):2235-2238.

83. Sharma P, Maffulli N. Biology of tendon injury: healing, modeling and remodeling. J Musculoskelet Neuronal Interact. 2006;6(2):181-190.

84. Woo SL. Tissue engineering: use of scaffolds for ligament and tendon healing and regeneration. Knee Surg Sports Traumatol Arthrosc. 2009; 17(6):559-560.

85. Woo SL, Hildebrand K, Watanabe N, Fenwick JA, Papageorgiou CD, Wang JH. Tissue engineering of ligament and tendon healing. Clin Orthop Relat Res. 1999;(367 Suppl):S312-S323.

86. Woo SL, Buckwalter JA. AAOS/NIH/ORS workshop: injury and repair of the musculoskeletal soft tissues - Savannah, Georgia, June 18-20, 1987. J Orthop Res. 1988;6(6):907-931.

87. Oshiro W, Lou J, Xing X, Tu Y, Manske PR. Flexor tendon healing in the rat: a histologic and gene expression study. J Hand Surg Am. 2003; 28(5):814-823.

88. Hildebrand KA, Frank CB, Hart DA. Gene intervention in ligament and tendon: current status, challenges, future directions. Gene Ther. 2004; 11(4):368-378.
89. Sharma P, Maffulli N. Tendon injury and tendinopathy: healing and repair. J Bone Joint Surg Am. 2005;87(1):187-202.

90. Manske PR, Lesker PA. Biochemical evidence of flexor tendon participation in the repair process: an in vitro study. J Hand Surg Br. 1984;9(2):117-120.

91. Gelberman RH, Manske PR, van de Berg JS, Lesker PA, Akeson WH. Flexor tendon repair in vitro: a comparative histologic study of the rabbit, chicken, dog, and monkey. J Orthop Res. 1984;2(1):39-48.

92. Koob TJ, Summers AP. Tendon: bridging the gap. Comp Biochem Physiol A Mol Integr Physiol. 2002;133(4):905-909.

93. Klein MB, Pham H, Yalamanchi N, Chang J. Flexor tendon wound healing in vitro: the effect of lactate on tendon cell proliferation and collagen production. J Hand Surg Am. 2001;26(5):847-854.

94. Riederer-Henderson MA, Gauger A, Olson L, Robertson C, Greenlee TK Jr. Attachment and extracellular matrix differences between tendon and synovial fibroblastic cells. In Vitro. 1983;19(2): 127-133.

95. Yang G, Rothrauff BB, Tuan RS. Tendon and ligament regeneration and repair: clinical relevance and developmental paradigm. Birth Defects Res C Embryo Today. 2013;99(3):203-222.

96. Bjordal JM, Lopes-Martins RA, Iversen VV. A randomised, placebo controlled trial of low level laser therapy for activated Achilles tendinitis with microdialysis measurement of peritendinous prostaglandin E2 concentrations. Br J Sports Med. 2006;40(1):76-80.

97. Reddy GK, Stehno-Bittel L, Enwemeka CS. Laser photostimulation of collagen production in healing rabbit Achilles tendons. Lasers Surg Med. 1998;22(5):281-287.

98. Salate AC, Barbosa G, Gaspar P, et al. Effect of In-Ga-Al-P diode laser irradiation on angiogenesis in partial ruptures of Achilles tendon in rats. Photomed Laser Surg. 2005;23(5):470-475.

99. de Jesus JF, Spadacci-Morena DD, Rabelo ND, Pinfildi CE, Fukuda TY, Plapler H. Low-level laser therapy in IL-1 $\beta$, COX-2, and PGE2 modulation in partially injured Achilles tendon. Lasers Med Sci. 2015; 30(1):153-158.

100. Casalechi HL, Leal-Junior EC, Xavier M, et al. Low-level laser therapy in experimental model of collagenase-induced tendinitis in rats: effects in acute and chronic inflammatory phases. Lasers Med Sci. 2013;28(3):989-995.

101. Bjordal JM, Lopes-Martins RA, Joensen J, et al. A systematic review with procedural assessments and meta-analysis of low level laser therapy in lateral elbow tendinopathy (tennis elbow). BMC Musculoskelet Disord. 2008;9:75.

102. Tumilty S, Munn J, McDonough S, Hurley DA, Basford JR, Baxter GD. Low level laser treatment of tendinopathy: a systematic review with meta-analysis. Photomed Laser Surg. 2010;28(1):3-16.

103. Nogueira AC Jr, Junior MJ. The effects of laser treatment in tendinopathy: a systematic review. Acta Ortop Bras. 2015;23(1):47-49.

104. Ogden JA, Tóth-Kischkat A, Schultheiss R. Principles of shock wave therapy. Clin Orthop Relat Res. 2001;387:8-17.

105. Wang CJ. An overview of shock wave therapy in musculoskeletal disorders. Chang Gung Med J. 2003;26(4):220-232.

106. Thiel M. Application of shock waves in medicine. Clin Orthop Relat Res. 2001;(387):18-21.

107. Wang CJ. Extracorporeal shockwave therapy in musculoskeletal disorders. J Orthop Surg Res. 2012;7:11.

108. Mani-Babu S, Morrissey D, Waugh C, Screen H, Barton C. The effectiveness of extracorporeal shock wave therapy in lower limb tendinopathy: a systematic review. Am J Sports Med. 2015;43(3):752-761.

109. Chen YJ, Wang CJ, Yang KD, et al. Extracorporeal shock waves promote healing of collagenase-induced Achilles tendinitis and increase TGF- $\beta 1$ and IGF-I expression. J Orthop Res. 2004;22(4):854-861.

110. Bosch G, Lin YL, van Schie HT, van de Lest CH, Barneveld A, van Weeren PR. Effect of extracorporeal shock wave therapy on the biochemical composition and metabolic activity of tenocytes in normal tendinous structures in ponies. Equine Vet J. 2007;39(3): 226-231. 
111. Wang CJ, Wang FS, Yang KD, et al. Shock wave therapy induces neovascularization at the tendon-bone junction: a study in rabbits. J Orthop Res. 2003;21(6):984-989.

112. Wang CJ, Huang HY, Pai CH. Shock wave-enhanced neovascularization at the tendon-bone junction: an experiment in dogs. J Foot Ankle Surg. 2002;41(1):16-22.

113. Zhang D, Kearney CJ, Cheriyan T, Schmid TM, Spector M. Extracorporeal shockwave-induced expression of lubricin in tendons and septa. Cell Tissue Res. 2011;346(2):255-262.

114. Hart L. Shock-wave treatment was more effective than eccentric training for chronic insertional Achilles tendinopathy. Clin J Sport Med. 2009;19(2):152-153.

115. Hsu CJ, Wang DY, Tseng KF, Fong YC, Hsu HC, Jim YF. Extracorporeal shock wave therapy for calcifying tendinitis of the shoulder. J Shoulder Elbow Surg. 2008;17(1):55-59.

116. Dean BJ, Lostis E, Oakley T, Rombach I, Morrey ME, Carr AJ. The risks and benefits of glucocorticoid treatment for tendinopathy: a systematic review of the effects of local glucocorticoid on tendon. Semin Arthritis Rheum. 2014;43(4):570-576.

117. McCoy BJ, Diegelmann RF, Cohen IK. In vitro inhibition of cell growth, collagen synthesis, and prolyl hydroxylase activity by triamcinolone acetonide. Proc Soc Exp Biol Med. 1980;163(2):216-222.

118. Walmsley GG, Maan ZN, Wong VW, et al. Scarless wound healing: chasing the holy grail. Plast Reconstr Surg. 2015;135(3):907-917.

119. Smidt N, Assendelft WJ, van der Windt DA, Hay EM, Buchbinder R, Bouter LM. Corticosteroid injections for lateral epicondylitis: a systematic review. Pain. 2002;96(1-2):23-40.

120. Kleinman M, Gross AE. Achilles tendon rupture following steroid injection: report of three cases. J Bone Joint Surg Am. 1983;65(9): 1345-1347.

121. Lu H, Yang H, Shen H, Ye G, Lin XJ. The clinical effect of tendon repair for tendon spontaneous rupture after corticosteroid injection in hands: a retrospective observational study. Medicine (Baltimore). 2016;95(41):e5145.

122. Jain K, Asad M, Joshi Y, Syed A. Tibialis anterior tendon rupture as a complication of first tarsometatarsal joint steroid injection: a case report and review of literature. Foot (Edinb). 2015;25(3):179-181.

123. Muto T, Kokubu T, Mifune Y, et al. Temporary inductions of matrix metalloprotease-3 (MMP-3) expression and cell apoptosis are associated with tendon degeneration or rupture after corticosteroid injection. J Orthop Res. 2014;32(10):1297-1304

124. Mahler F, Fritschy D. Partial and complete ruptures of the Achilles tendon and local corticosteroid injections. Br J Sports Med. 1992; 26(1):7-14

125. Gill SS, Gelbke MK, Mattson SL, Anderson MW, Hurwitz SR. Fluoroscopically guided low-volume peritendinous corticosteroid injection for Achilles tendinopathy: a safety study. J Bone Joint Surg Am. 2004;86A(4):802-806.
126. Nicholson LT, DiSegna S, Newman JS, Miller SL. Fluoroscopically guided peritendinous corticosteroid injection for proximal hamstring tendinopathy: a retrospective review. Orthop J Sports Med. 2014;2(3): 2325967114526135.

127. Chen CH, Cao Y, Wu YF, Bais AJ, Gao JS, Tang JB. Tendon healing in vivo: gene expression and production of multiple growth factors in early tendon healing period. J Hand Surg Am. 2008;33(10):1834-1842.

128. Costa MA, Wu C, Pham BV, Chong AK, Pham HM, Chang J. Tissue engineering of flexor tendons: optimization of tenocyte proliferation using growth factor supplementation. Tissue Eng. 2006;12(7): 1937-1943.

129. Castillo TN, Pouliot MA, Kim HJ, Dragoo JL. Comparison of growth factor and platelet concentration from commercial platelet-rich plasma separation systems. Am J Sports Med. 2011;39(2):266-271.

130. de Vos RJ, Weir A, van Schie HT, et al. Platelet-rich plasma injection for chronic Achilles tendinopathy: a randomized controlled trial. JAMA. 2010;303(2):144-149.

131. Santo VE, Gomes ME, Mano JF, Reis RL. Controlled release strategies for bone, cartilage, and osteochondral engineering - part I: recapitulation of native tissue healing and variables for the design of delivery systems. Tissue Eng Part B Rev. 2013;19(4):308-326.

132. Evans $C$. Using genes to facilitate the endogenous repair and regeneration of orthopaedic tissues. Int Orthop. 2014;38(9):1761-1769.

133. Evans CH. Gene delivery to bone. Adv Drug Deliv Rev. 2012;64(12): 1331-1340.

134. Delalande A, Gosselin MP, Suwalski A, et al. Enhanced Achilles tendon healing by fibromodulin gene transfer. Nanomedicine. 2015;11(7): 1735-1744.

135. Killian ML, Cavinatto L, Galatz LM, Thomopoulos S. The role of mechanobiology in tendon healing. J Shoulder Elbow Surg. 2012; 21(2):228-237.

136. Boyer MI, Goldfarb CA, Gelberman RH. Recent progress in flexor tendon healing: the modulation of tendon healing with rehabilitation variables. J Hand Ther. 2005;18(2):80-86.

137. Thomopoulos S, Williams GR, Soslowsky LJ. Tendon to bone healing: differences in biomechanical, structural, and compositional properties due to a range of activity levels. J Biomech Eng. 2003;125(1): 106-113.

138. Kishore V, Bullock W, Sun X, van Dyke WS, Akkus O. Tenogenic differentiation of human MSCs induced by the topography of electrochemically aligned collagen threads. Biomaterials. 2012;33(7): 2137-2144.

139. Moffat KL, Kwei AS, Spalazzi JP, Doty SB, Levine WN, Lu HH. Novel nanofiber-based scaffold for rotator cuff repair and augmentation. Tissue Eng Part A. 2009;15(1):115-126.

\section{Publish your work in this journal}

Drug Design, Development and Therapy is an international, peerreviewed open-access journal that spans the spectrum of drug design and development through to clinical applications. Clinical outcomes, patient safety, and programs for the development and effective, safe, and sustained use of medicines are the features of the journal, which

\section{Dovepress}

has also been accepted for indexing on PubMed Central. The manuscript management system is completely online and includes a very quick and fair peer-review system, which is all easy to use. Visit http://www.dovepress.com/testimonials.php to read real quotes from published authors. 